\title{
Discussion on Philosophy of Information and Artificial Intelligence
}

\author{
Kaiyan Da, Guojian Cheng \\ School of Intelligent Science \& Information Engineering \\ Xi'an Peihua University, Xi'an, China \\ katherine@peihua.cn
}

Keywords: Philosophy of Information; Artificial Intelligence; Information Thinking

\begin{abstract}
For the first time, the philosophy of information puts forward the world view of "the dual existence of material and information" and reclassifies the area of existence. It's viewpoint of "existence $=$ material + information" establishes the theoretical origin of the information ontology and clarifies the value of the existence of information. Artificial intelligence is a new technical science for researching and developing theories, methods, technologies and application systems for simulating, extending and expanding human intelligence. The relationship between artificial intelligence and philosophy of information is very close. As a new philosophical principle or paradigm, philosophy of information has important guiding significance for the research and development of artificial intelligence.
\end{abstract}

\section{Introduction}

Since the late $20^{\text {th }}$ century, the worldwide information technology revolution, the rise of the information economy and the information society, and the development and progress of the scientific information science, the social information and the socialization of information all call for the birth of a new philosophy in the new era. In 1985, Mr. Wu Kun published his paper "An Introduction to Philosophy of Information Theory". Later in 1987, he published the book "Introduction to Philosophy of Information Theory", which marked the official founding of philosophy of information in China. He particularly emphasized that since the philosophy of information has clarified a brand-new segmentation model of existence, it has fundamentally changed the specific expression of the basic issues of philosophy. Therefore, philosophy of information is called a meta-philosophy or supreme philosophy. The philosophy of information realized the first fundamental shift in human philosophy, and thus led to a full range of fundamental changes in human philosophy.

\section{What is Philosophy of Information?}

\subsection{Definition of Philosophy of Information}

Materialistic philosophy holds that: "material is the first nature, and spirit is the second nature; material decides spirit; spirit is the product of the development of the material world, and it is the human brain's reflection of objective things ( from Principles of Marxist Philosophy). In other words, Marxist philosophical materialism holds that the world is composed of "dual existence of material and spirit". The entire world is a material world that does not rely on human spirit but exists objectively. The original world is material which has a decisive role on spirit and spirit is a reflection of material. Spirit is not spontaneous and transcendental. The form of understanding the world is subjective while the content of understanding the world is objective. Based on the materialism of Marxist philosophy, the philosophy of information first proposed the world view of "the dual existence of material and information" and redefined the area of existence, arguing that "existence = material + information" and established the theory of information ontology, which clarified the existential value of information, provided a new theoretical source for the development of philosophy in the new era, and then triggered all-round fundamental changes in all other fields of philosophy. Therefore, it is called philosophy prima, the highest philosophy and first philosophy. 


\subsection{Some Basic Theories of Philosophy of Information}

Philosophy of information treats information as an existence, not just as a method. The philosophy of information holds that existence exists in both objective existence and subjective existence; since objective existence is not all real, objective existence is divided into objective reality and objective unreality. Compared with objective reality, subjective existence and objective unreality are merely reflections of the objective world. Therefore, they can be collectively referred to as indirect existence. Such indirect existence is information. In short, direct existence is material, and indirect existence is information. Therefore, we can define the information from the perspective of philosophical ontology: information is the philosophical category that marks the indirect existence (1984, Wu Kun), and it is the self-display of the existing way and state of material (direct existence) (1981, Wu Kun).

Cognition is a process of information activity with advanced information response. There are four aspects of the unified interaction process between the levels of subject information activities, namely, the construction relationship of the levels of subject information activities, the holographic control relationship of the levels of subject information activities from top to bottom, the comprehensive participation of the levels of subject information activities and the mutual transformation of the levels of subject information activities.

The philosophy of information puts forward a new theory of epistemology- the philosophical epistemology of information intermediary theory. This theory includes two aspects: the first is the information intermediary theory $(1984, \mathrm{Wu}$ Kun), and the second is the information construction and simulation of cognitive processes and mechanisms. The interaction between subject and object is a complex multi-level intermediary process. The first intermediary link of object recognizing subject is the object information field; the second intermediary link is the physiological structure of the subject's own nervous system; the third intermediary link is the cognitive structure that the subject has constructed, and the fourth intermediary link is the physical means of understanding the subject (tools, instruments and facilities etc.) Based on this, human information recognition processes and mechanisms can be summarized as discriminating on the basis of differences, constructing on the basis of the intermediary, and virtualizing on the basis of construction.

\section{What is Artificial Intelligence?}

\subsection{Definition of Artificial Intelligence}

Artificial Intelligence is abbreviated for AI. It is a new technical science that studies and develops the theory, methods, technologies, and application systems for simulating, extending, and expanding human intelligence. AI is a branch of computer science. It attempts to understand the essence of intelligence and produces a new intelligent machine that can respond in a similar way to human intelligence. Research in this area includes robots, language recognition, image recognition, natural language processing and expert systems. Since the birth of AI, theory and technology have become increasingly mature, and the application fields have also been expanding. It can be assumed that the technological products brought by AI in the future will be the "containers" of human wisdom. AI can simulate the information process of human spirit and thinking. AI is not human intelligence, but it can be thought of as human beings, and it can also exceed human intelligence. AI is a very challenging science. The person engaged in this work must understand computer knowledge, psychological knowledge and philosophical knowledge, and philosophy of information just provides theoretical guidance for the research of AI.

\subsection{Information and AI}

As mentioned earlier, we can define information from the perspective of philosophical ontology as: information is the philosophical category that marks the indirect existence, and it is the self-display of the existing way and state of material (direct existence). The philosophical ontological basis of AI 
comes from the Philosophy Theory of ancient Greek Plato's philosophy and the Deterministic Theory of Mathematics of the Pythagorean school.

As a direct reflection of the existence and state of material (direct existence), information plays a very important role in the development of AI. In the era of PC internet of things, there are two major technologies that are driving the development of AI. The first is digitalization of all things, and the second is big data technology. A new generation of information technology platforms can more effectively achieve the connection and communication between people and information to achieve further development of human-computer interaction. As a branch of computer science, AI is, in its essence, a simulation of the information process of human thinking. The mathematical basis of "machine learning" is statistics,information theory and cybernetics.

\subsection{Philosophy of Information and AI}

According to the viewpoint of Marxist philosophy, philosophy serves as a general rule for revealing the development of the entire world, providing world vision and methodological guidance for people to understand the world and transform the world. The specific science reveals the laws of a particular field, and provides a concrete method for people to understand the world and transforming the world. Therefore, the specific science is the basis of philosophy. The progress of specific science promotes the development of philosophy. Philosophy provides the guidance of world vision and methodology for specific science. The philosophy of information is an inevitable product of the development of human information age and the development of philosophy. It is a complete system with core theory of material and information. As a world vision, methodology and values in the new era, as a new philosophy or paradigm, philosophy of information can guide the research and development of this specific science- artificial intelligence.

\section{The Significance of Philosophy of Information in the Research and Development of AI}

\subsection{Information Thinking for AI}

The philosophy of information has broken the traditional materialistic and spiritual dualist view, and regards material and information as two existential modes of the world. This kind of Information Thinking has given ontological importance to the long-overlooked information dimension that constitutes the world. The Information Thinking "grasps and describes the nature, characteristics and attributes of things from the structure and relationship patterns, evolutionary processes, and process models of existing things. It uses the structure, relationships and processes of existing things as the carrier and password of information and deciphers the content, meaning, and value of the indirect existence of historical states, real relationships and future tendencies that are contained in them. In addition, the Information Thinking will also turn realistic objectification to artificial symbolization, and will give it a specific representative relationship." (Complexity and Information Science Research Program by Wu Kun). This theoretical perspective and research methods provide the most basic and core theoretical paradigm for the research and development of AI.

\subsection{Epistemology of Philosophy of Information for Researching Cognitive Activities}

From the perspective of the philosophy of information, human cognitive activities are information-building and virtual activities that relatively move in multilevel intermediary. Due to the special nature of AI, its research should follow the path and method of information science research program and Information Thinking, and start from information which is long-neglected to decode and recode human cognitive activities. Probing the order of the micro-information coding framework of mental activity, deciphering the nature, function, meaning, and value of mental history, current status and future as defined in it, creating the nature and function of the overall holographic mapping system in the overall synthesis of the micro-information coding framework of the cognitive system, exploring or clarifying the specific mechanisms of the mutative changes in the coding framework of cognitive system information caused by random or occasional microscopic or macroscopic 
information interaction or interference, it is a feasible approach and method for the research of the complexity to AI.

\section{Conclusions}

In short, the relationship between AI and philosophy of information is very close. AI itself is an obvious complicated issue in terms of ontology, epistemology and linguistics. From the perspective of the characteristics of AI itself, the information science program is a scientific research field that is more suitable for the development of AI. In other words, as a brand-new philosophical principle or paradigm, philosophy of information has important guiding significance for the research and development of AI.

\section{References}

[1] Artificial Intelligence. https://baike.so.com/doc/2952526-3114987.html.

[2] Li Guowu: Research on Philosophy of Information Science of Wu Kun [M]. Beijing. China Social Sciences Press. 2015

[3] Complete Works of Marx and Engels (first volume) [M]. Beijing. People's Publishing House. 1995

[4] Wu Kun: Philosophy of Information--A New Time Spirit [M] . Xi'an. Shaanxi Normal University Press. 1989

[5] Wu Kun: The Division of Existence and the Meaning of New Philosophical Revolution in Philosophy of Information [J]. Humanities Magazine. 2013(5)

[6] Wu Kun: Philosophy of Information - Theory, System and Method [M]. Beijing. Commercial Press. 2005

[7] Wu Kun: Basic Problems of Philosophy and Fundamental Changes in Philosophy [J]. Hebei Journal. 2011(4)

[8] Joseph E. Brenner: Wu Kun and The Metaphilosophy of Information [J]. Information Theories and Applications. 2011(2)

[9] Konstantin Kolin. Philosophical Problems in Information Science [M]. Beijing. China Social Sciences Press. 2012.

[10] Chamiak E \& Reisbeck C. K. \& Meehan JR.: Artificial Intelligence Programming [J]. Lawrence Erbaum Associates. 1996

[11] George F.Luger: Artificial Intelligence Structures and Strategies for Complex Problem Solving [M] . China Machine Press, 2004

[12] Griffin M.: An 11 Million Transistor Digital Neural Network Execution Engine. The IEEE International Solid State Circuits Conference, San Francisco, CA, 1991

[13] M.N. Huhns: Distributed Artificial Intelligence, Morgan Kaufmann Publishers, Inc., 1987

[14] Ju-Y.D.Yang, M.N. Huhns, L.M. Stephens: An Architecture for Control and Communication in Distribute Artificial Intelligence Systems, IEEE Transactions on Systems, Man and Cybernetics, Vol.SMS-15, No.3, pp317-326,1985.

[15] X. Jiang and H. Bunke: Vision Planner for An Intelligence Multisensory Vision System. Technical Report, University of Bern (extended version of a paper appearing in ICPR 1994). 